TP Periodica Polytechnica Chemical Engineering

60(1), pp. 24-28, 2016

DOI: $10.3311 /$ PPch. 7997

Creative Commons Attribution (i)

RESEARCH ARTICLE

\section{Generation of Simulation Based} Operational Database for an Acid Gas Removal Plant with Automatic Calculations

Bálint Silhavy ${ }^{1,2}$, Lajos Erdős², Péter Mizsey ${ }^{1 *}$, Katalin Koczka ${ }^{1}$, Ágnes Szanyi ${ }^{1}$, László Mika ${ }^{1}$, Tamás Benkő ${ }^{1}$

Received 24 February 2015; accepted after revision 26 June 2015

\begin{abstract}
Computer aided process design is improving with newer and newer tools. One of such tools is the automatic calculation technique that enables the combination of different software tools to enhance the efficiency of the calculations. In our research work Aspen HYSYS model of a petrochemical plant is built in order to simulate responses of an existing plant to the changes in the composition and amount of feed material. The Aspen HYSYS is connected to Microsoft Excel program; simulated operational data are stored in an operational database and transported to Excel for further analysis. The automatic calculation completed with the two software tools mutually strengthens their merits and results in enhanced insight into the operational features of any plant. Comparison of the projected input parameters of the petrochemical plant studied shows that the extension of the plant is badly needed. Cash-flow analysis suggests that the extension is profitable.
\end{abstract}

\section{Keywords}

Simulation, automatic calculation, operational database, acid gas removal

\section{Introduction}

Computer based modelling has been continuously improving in order to help the engineers more and more at process design and decision making. By now a lot of professional process simulators (Aspen HYSYS [1], Aspen Plus [2], ChemCAD [3], gPROMS [7], SimSci PRO/II [14], UniSim Design Suite [19]) and optimization methods [e.g. 8,10-13,15,18,20] have been already developed. In this study we introduce a new method, automatic calculations [5], for the quick analysis of a complex system. The accuracy of our new method is presented on the example of an amine gas treatment plant.

Natural gases produced in Hungary usually contain significant amounts of acidic gases, such as $\mathrm{CO}_{2}$ and $\mathrm{H}_{2} \mathrm{~S}$. Therefore natural gas treatment has to include an acidic gas removal step for meeting the quality requirements of the sales gas and for protecting the gas pipelines from corrosion.

In the natural gas industry one of the widespread technologies for acidic gas removal is the amine absorption, as pointed out by Gadelha et al. [6]. The amine gas treatment plants have two major blocks, one is the absorber in which the acidic gas removal is taking place and the other one is the amine regenerator unit that is a desorber. The amine absorption is a very complex process; a lot of process simulator programs and manual optimization methods [16,17] were already developed. Application of software in the industry for optimization and cost reduction is a widely established procedure. However, linkage and integration of different software tools into a common unit providing more and easily interpretable results is not prevalent. In this study an all-around operational database of the acid gas removal plant is created based on the simulations for various operational conditions. This database can be useful for the operators and the decision makers of the plant.

\section{Data and methods}

In order to carry out the technological calculations with a professional process simulator, first we developed the simulation of the plant. For the calculations Aspen HYSYS professional process simulator was used. The software provides a basic 


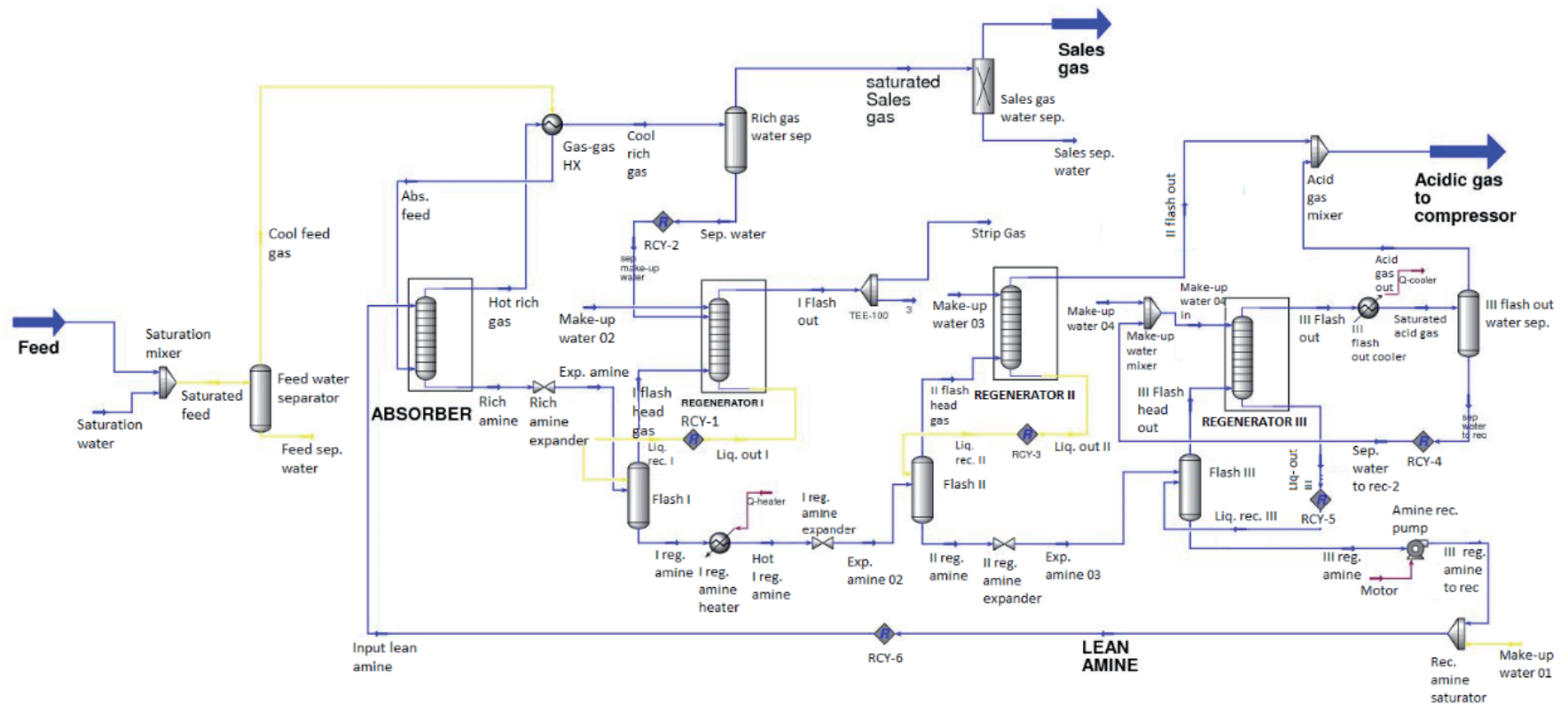

Fig. 1 Process flow diagram of the acid gas removal process.

operational environment into which any operational unit, such as columns, separators or heat exchangers can be easily inserted.

\subsection{Model of the acid gas removal plant}

There are two types of amine gas treatment plants. The difference between them is the process of the absorbent regeneration. In the first type the used amine is regenerated in a reboiled desorber column [9]. In the second type the regeneration is carried out mainly by decreasing the pressure. This way more columns are needed for the regeneration process. However, by omitting the reboiler, the energy consumption of the plant is much lower than in the first type.

The flowsheet of the plant examined is shown in Fig. 1. The process flow diagram and the model are developed according to an existing acid gas removal plant; therefore the geometric and rating data were available. The model can be verified by the comparison of simulation results and measured data.

\subsection{Validation of the model}

Validation is carried out by comparing the on-site measured parameters with the calculated parameters. A measured dataset is obtained from continuously recorded data of the existing plant. Mean values of the recorded data are determined for 4-hour-long periods. Data from 9 recording periods were available for the validation of the model. It should be noted that time-mean values of the measured and recorded data do not represent total steady-state but describe a usual situation in the investigated acid gas removal plant.

For the validation of the modelled data, the most accurately monitored parameters are the most convenient to investigate and compare. In the case of an amine treatment plant these parameters are (a) quantity, (b) lower heating value (LHV), and (c) Wobbe Index of the sales gas [4].
Properties of the feed stream during the recording periods were used as input for the simulations aiming at the validation.

\subsection{Software integration}

Complex technological calculations can be carried out quickly by a process simulator; however, resetting the input parameters can be time consuming, moreover, storage of the simulation results is not quite resolved, although these are common costumer demands. According to this, extended application of Aspen HYSYS is required and performed with linking the Aspen HYSYS simulator with MS Excel. MS Excel allows resetting input parameters and supervises operations of the process simulator. As the storage capacity of the MS Excel is practically unlimited, it is an ideal co-operating partner for the process simulator. Other advantage of this coupling is that both software can be programmed in VBA (Visual Basic for Applications) language. The mutual connection between Aspen HYSYS and MS Excel is created by an interface software called HysysBrowser.

A series of technological calculations were carried out with the help of this software connection. The input parameters for every simulation were always set in MS Excel and transferred to Aspen HYSYS via HysysBrowser. When a technological calculation was carried out by the process simulator, the results were transferred back to MS Excel.

During a series of calculations, the scrolling bugs can easily spoil the results. Therefore the HysysBrowser has an in-built safety system, which aborts the calculations if a simulation does not have a convergent result.

\subsection{Automated simulations}

In order to scan the whole operational range of the plant, the relevant ranges of the input parameters were determined. In an amine gas treatment plant the most important input parameters 


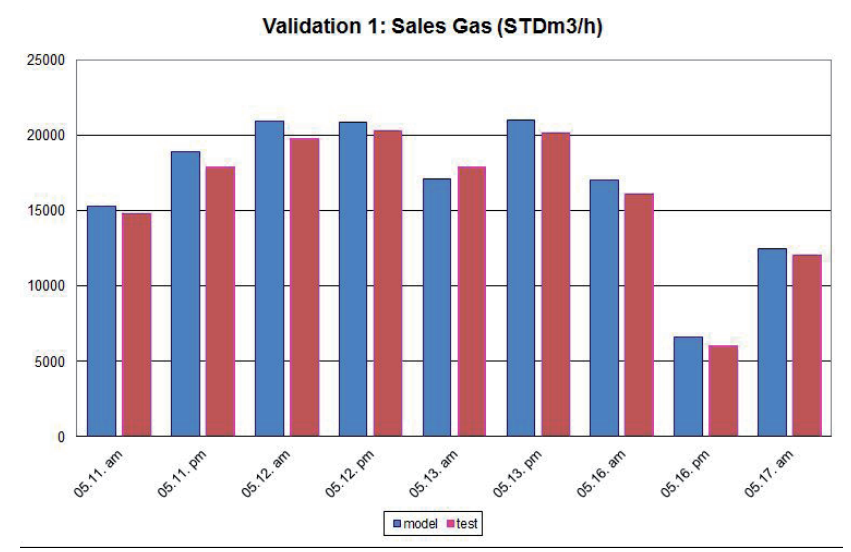

Fig. 2 Measured and calculated volumetric flow of the sales gas during the recording periods.

are: quantity and acidic gas content of the raw natural gas, type and quantity of the used amine, operational temperatures and pressures of the columns. As processes of an existing amine treatment plant were simulated, parameters of the amine and parameters of the columns were known and applied in the model. Therefore, two input parameters remain that can be specified by the user: (a) volumetric flow, and (b) acidic gas content of the natural gas entering the plant (Feed).

In our simulations input parameters were varied within the following limits: $20000-60000$ Standard (STD) $\mathrm{m}^{3} / \mathrm{h}$ natural gas (step size: $5000 \mathrm{STDm}^{3} / \mathrm{h}$ ); and $1050 \mathrm{~V} / \mathrm{V} \%$ acidic gas content (step size: $1 \mathrm{~V} / \mathrm{V} \%$ ). Sequence of the calculations was determined before starting the simulations. A parameter step schedule was built and applied that enables huge amount of simulations one after another without any user interaction requirements which makes the task more user friendly.

A series of calculations were carried out systematically in the order of a pre-determined step-schedule, called automatic calculations by Erdős and Németh (2010). Simulation results transferred back to MS Excel, input and output data were shown in the same line of the MS Excel file from which the particular simulation started. At the end of the calculations, the initial parameters and the calculation results were displayed in a structured form in the MS Excel file. Thus, the operational database of the amine gas treatment plant was created.

The size of this database depends on the number of the parameters defined by the user. A small database can only contain the most important calculation results; a larger one can easily contain nearly every parameter of the plant. There is no real difference in time between the creation of a full database with all the parameters of the plant and a basic database showing only the most important results. Therefore the creation of an all-around database is recommended.

This database can be easily improved with the addition of graphs enabled by the MS Excel environment and data processing in order to show the results of the calculations graphically. This option makes it easier to draw conclusions about the operation of the plant.

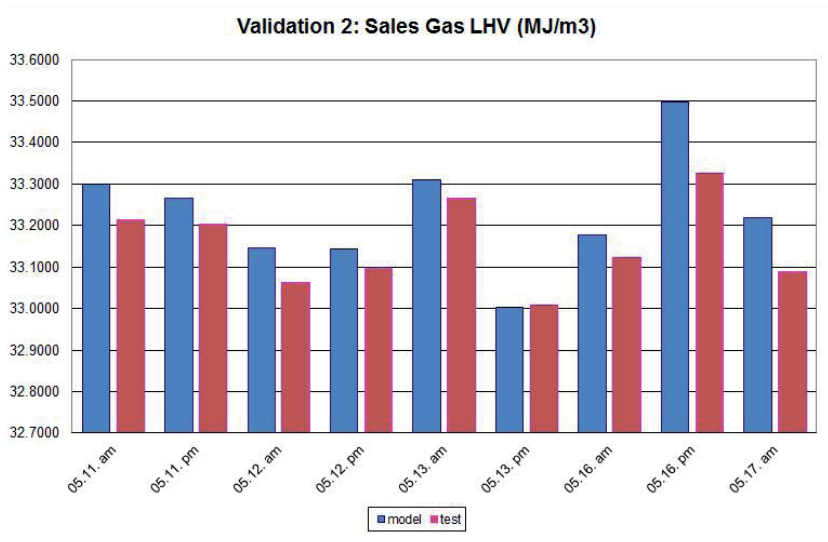

Fig. 3 Measured and calculated LHV of the sales gas during the recording periods.

\section{Results and discussion}

\subsection{Validation of the plant model}

At the validation of the plant model, volumetric flow of the product (sales gas), its LHV and Wobbe Index were compared. Measured data representing the nearly steady-state of the plant and simulation data modelling the plant during the recording periods. Feed stream was defined according to the properties of the actual feed of the plant for these periods. Error of the model is defined as the ratio of the difference between simulation and measured data related to the simulated value, that is, a simple percentage calculation.

Calculated and measured volumetric flow values of the product streams are shown in Fig. 2. It can be concluded that the model overestimates the volumetric flow in most of the cases within the range of the relative error of 2.8-9.9\%, which is acceptable in this case. Error of LHV and Wobbe Indices are, however, lower: 0.01-0.5\%

As the evaluation of the results shown in Fig. 2 - 4, it can be concluded that the simulation is reliable and valid for further calculations.

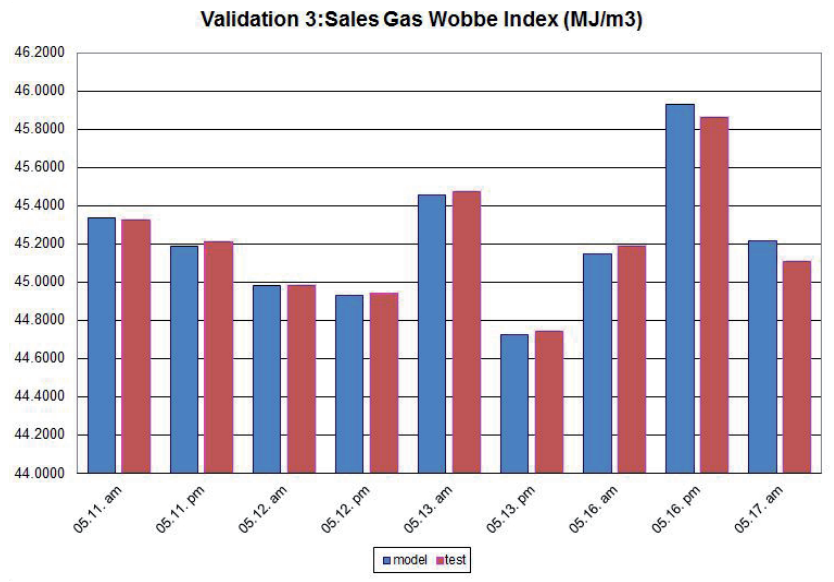

Fig. 4 Measured and calculated Wobbe index of the sales gas during the recording periods. 
Table 1 Calculated acidic gas content limits in the feed.

\begin{tabular}{|c|c|c|c|c|c|c|c|c|c|}
\hline Natural gas $(1,000 \mathrm{STDm} 3 / \mathrm{h})$ & 20 & 25 & 30 & 35 & 40 & 45 & 50 & 55 & 60 \\
\hline Max. acidic gas content (V/V\%) & 44 & 36 & 30 & 27 & 24 & 22 & 20 & 19 & 17 \\
\hline
\end{tabular}

Table 2 Projected feed gas parameters and treatability with the existing acid removal plant.

\begin{tabular}{llllllll}
\hline Year & 2014 & 2015 & 2016 & 2017 & 2018 & 2019 & 2020 \\
\hline Natural gas (1,000 STDm3/h) & 46 & 44 & 47 & 45 & 43 & 41 & 38 \\
Max. acidic gas content (V/V\%) & 25 & 27 & 25 & 26 & 27 & 28 & 30 \\
Treatable with current facility or not (Y/N) & $\mathrm{N}$ & $\mathrm{N}$ & $\mathrm{N}$ & $\mathrm{N}$ & $\mathrm{N}$ & $\mathrm{N}$ & $\mathrm{N}$ \\
\hline
\end{tabular}

\subsection{Operational database}

Operational database of the amine gas treatment plant was created under varying the flow and composition of the feed stream. Those cases of the operational database were technically acceptable where the product (sales gas) fulfilled the pipeline quality requirements defined through LHV and Wobbe Index. According to this, operational limits of the existing plant can be determined by extracting those cases from the operational database, where the product fulfils the pipeline requirements. Table 1 shows those input parameter pairs where the pipeline quality was reached. As Table 1 shows, the plant works properly for small amounts of natural gas even if it contains high concentrations of acidic gases. However, as the pipeline quality should be met, the increase of the feed gas quantity allows only lower acidic gas concentrations in the feed. Thus, the absorption capacity of the plant depends on the absolute amount of the acidic gas in the input gas.

The operational database is very useful to determine whether a natural gas is treatable or not in the plant. It is enough just to check the projected compositions and quantities of the natural gases planned to be exploited in the area and compare it to the database. Such projected exploitation data for future years are shown in Table 2. The evaluation of these future cases, whether the projected quantities and composition can be processed at the current plant, are also shown in Table 2. It can be concluded that due to the decreasing quality of the input gases the plant will not be able to treat the projected exploited gases. Thus, the extension of the plant is necessary for further operations.

As it turned out from further examinations, regeneration capacity of the plant is the limiting parameter. Thus, the installation of an additional reboiled desorber would be necessary in order to enhance the efficiency of the amine regeneration. More efficient amine regeneration would increase the capacity of the plant. Later, economic calculations of the recommended capacity enhancement were carried out. These calculations indicated a 2-year-long payoff period.

\section{Conclusions}

In this study a new and extremely fast method, the automatic calculations, is shown and being applied to create an operational database for an existing industrial acid gas removal plant. This method is based on the same programmability of Aspen HYSYS and MS Excel. It combines the strengths of both software tools. The automatic calculation improves the efficiency of the process modelling and helps engineers at process investigation saving routine human work. The created database is an extremely valuable document for a plant as it is shown on a particular case study. The automatic calculations can be a useful tool for solving different process modelling problems.

\section{References}

[1] Aspen HYSYS. [Online] Available from: http://www.aspentech.com/ products/aspen-hysys.aspx

[2] Aspen Plus. [Online] Available from: http://www.aspentech.com/products/aspen-plus.aspx

[3] ChemCAD [Online] Available from: http://www.chemstations.com

[4] EASEE. European Association for the Streamlining of Enegy Exchange - Harmonisation of Natural Gas Quality. [Online] 2005. Available from: http://easee-gas.eu/media/4085/cbp\%202005-001-02\%20 3.pdf

[5] Erdős, L., Németh, Gy. "Analysis of simple and complex technology systems with automated process-simulation technology." MOL Scientific Magazine. 2010/1. Workshop. p. 102-113. 2010.

[6] Gadelha, T. S., Guimarães, A. R. S., Nakao, A., Araújo, O. de Q. F., Madeiros, J. L. de "A Comparative Economical Analysis of Technologies for CO2 Removal from Offshore Natural Gas." Computer Aided Chemical Engineering. 31. pp. 800-804. 2012.

DOI: 10.1016/B978-0-444-59507-2.50152-9

[7] gPROMS. [Online] Available from: http://www.psenterprise.com/ gproms.html

[8] Lavric, V. "Process Design, Integration and Optimisation: Advantages, Challenges and Drivers." In: Klemeš, J. J. (ed.): Handbook of Process Integration (PI). Woodhead Publishing. pp. 79-125. 2013.

DOI: $10.1533 / 9780857097255.1 .79$

[9] Léonard, G., Mogador, B. C., Belletante, S., Heyen, G. "Dynamic modelling and control of a pilot plant for post-combustion $\mathrm{CO} 2$ capture." Computer Aided Chemical Engineering. 32. pp. 451-456. 2013. DOI: 10.1016/B978-0-444-63234-0.50076-2 
[10] Biegler, L. T., Grossmann, I. E., Westerberg, A. W. "Systematic Methods of Chemical Process Design." Prentice Hall, 1997.

[11] Ostrovsky, G. M., Ziyatdinov, N. N., Lapteva, T. V., Zaitsev, I. V. "Optimization of chemical processes with dependent uncertain parameters." Chemical Engineering Science. 83. pp. 119-127. 2012. DOI: $10.1016 /$ j.ces.2011.10.074

[12] Pham, Q. T. "Dynamic optimization of chemical engineering processes by an evolutionary method." Computers \& Chemical Engineering. 22. pp. 1089-1097. 1998. DOI: 10.1016/S0098-1354(97)00265-2

[13] Rao, S. S. "Engineering Optimization: Theory and Practice." 4th ed. John Wiley \& Sons. 2009. DOI: 10.1002/9780470549124

[14] SimSci PRO/II. [Online] Available from: http://software.invensys.com/ products/simsci/design/pro-ii/

[15] Steimel, J., Harrmann, M., Schembecker, G., Engell, S. "A framework for the modeling and optimization of process superstructures under uncertainty." Chemical Engineering Science. 115. pp. 225-237. 2014. DOI: $10.1016 /$ j.ces.2013.04.052

[16] Tock, L., Maréchal, F. "Process design optimization strategy to develop energy and cost correlations of $\mathrm{CO} 2$ capture processes." In: Lockhart Bogle, I. D., Fairweather, M. (eds.): Computer Aided Chemical Engineering. Elsevier, Vol. 30, pp. 562-566. 2012.

DOI:10.1016/B978-0-444-59519-5.50113-1
[17] Tock, L., Maréchal, F. "Process design optimization strategy to develop energy and cost correlations of $\mathrm{CO} 2$ capture processes." Computers \& Chemical Engineering. 61. pp. 51-58. 2014.

DOI: 10.1016/j.compchemeng.2013.10.011

[18] Towler, G., Sinnott, R. "Optimization in Design." In: Towler, G., Sinnott, R. (eds.): Chemical Engineering Design. 2nd ed. Boston: ButterworthHeinemann. pp. 525-553. 2013.

DOI: 10.1016/B978-0-08-096659-5.00012-2

[19] UniSim Design Suite. [Online] Available from: https://www.honeywellprocess.com/en-US/explore/products/advanced-applications/unisim/ Pages/unisim-design-suite.aspx

[20] Xiong, Q., Jutan, A. "Continuous optimization using a dynamic simplex method." Chemical Engineering Science. 58. pp. 3817-3828. 2003. DOI: 10.1016/S0009-2509(03)00236-7 